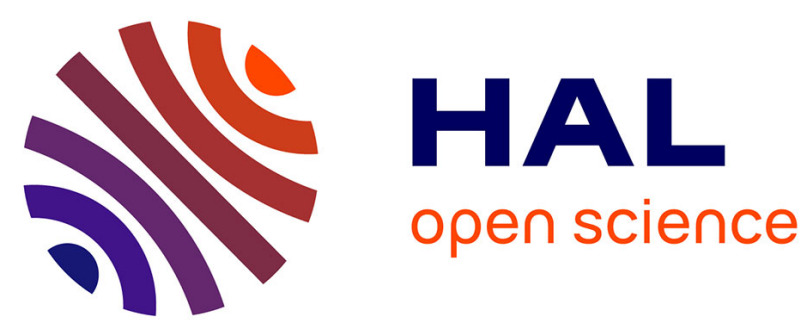

\title{
From flasks to single used bioreactor : scale-up of solid state fermentation process for metabolites and conidia production by Trichoderma asperellum
}

Hamrouni Rayhane, Molinet Josiane, Mitropoulou Gregoria, Kourkoutas Yiannis, Dupuy Nathalie, Masmoudi Ahmed, Roussos Sevastianos

\section{To cite this version:}

Hamrouni Rayhane, Molinet Josiane, Mitropoulou Gregoria, Kourkoutas Yiannis, Dupuy Nathalie, et al.. From flasks to single used bioreactor : scale-up of solid state fermentation process for metabolites and conidia production by Trichoderma asperellum. Journal of Environmental Management, 2019, 252, pp.109496. 10.1016/j.jenvman.2019.109496 . hal-02461940

\author{
HAL Id: hal-02461940 \\ https://hal.science/hal-02461940
}

Submitted on 31 Jan 2020

HAL is a multi-disciplinary open access archive for the deposit and dissemination of scientific research documents, whether they are published or not. The documents may come from teaching and research institutions in France or abroad, or from public or private research centers.
L'archive ouverte pluridisciplinaire HAL, est destinée au dépôt et à la diffusion de documents scientifiques de niveau recherche, publiés ou non, émanant des établissements d'enseignement et de recherche français ou étrangers, des laboratoires publics ou privés. 


\title{
From flasks to single used bioreactor: Scale-up of solid state fermentation process for metabolites and conidia production by Trichoderma asperellum
}

\author{
Hamrouni Rayhane ${ }^{\mathrm{a}, \mathrm{b}, \mathrm{d}, *}$, Molinet Josiane $^{\mathrm{a}}$, Mitropoulou Gregoria ${ }^{\mathrm{c}}$, Kourkoutas Yiannis ${ }^{\mathrm{c}}$, \\ Dupuy Nathalie $^{\mathrm{a}}$, Masmoudi Ahmed ${ }^{\mathrm{b}, \mathrm{d}}$, Roussos Sevastianos ${ }^{\mathrm{a}}$ \\ ${ }^{a}$ Aix Marseille Univ, Avignon Université, CNRS, IRD, IMBE, Marseille, France \\ ${ }^{\mathrm{b}}$ Univ. Manouba, ISBST, BVBGR-LR11ES31, Biotechpole Sidi Thabet, 2020, Ariana, Tunisia \\ ${ }^{\mathrm{c}}$ Laboratory of Applied Microbiology and Biotechnology, Department of Molecular Biology and Genetics, Democritus University of Thrace, University Campus, \\ Alexandroupolis, GR, 68100, Greece \\ ${ }^{\mathrm{d}}$ Univ Tunis El Manar, FST, Campus Universitaire, Tunis, Tunisia
}

Keywords:

Solid state fermentation

Single used bioreactor

Trichoderma asperellum

6-Pentyl-a-pyrone

Conidia

Lytic enzymes

\begin{abstract}
Currently, the increasing demand of biopesticides production to replace chemical pesticides which are excessively used has made solid state fermentation (SSF) technology the need of the hour. In spite of advantages, true potential of SSF process has not been fully realized at industrial scale. A fermentation process for 6-pentyl-apyrone (6 PP), conidia, and lytic enzymes (cellulases, lipase, amylase) production by Trichoderma asperellum TF1 was scaled-up from $250 \mathrm{~mL}$ flasks and glass Raimbault column packed with $20 \mathrm{~g}$ of solid substrates (dry weight) to $5 \mathrm{Kg}$ of solid substrate by using a new plastic single used bioreactor. For column and single used bioreactor, the fermentation was done with the application of humid air during all the process however flasks are not hermetically closed that some oxygen could flow by diffusion. T. asperellum growth was investigated using a mixture of vine shoots, jatropha cake, olive pomace and olive oil as substrate in all systems in parallel at $25^{\circ} \mathrm{C}$ during 7 days. Overall, the conditions applied on the single used bioreactor resulted in the optimum 6-PP production $\left(7.36 \pm 0.37 \mathrm{mg} \mathrm{g} \mathrm{DM}^{-1}\right)$, lipases $(38.73 \pm 0.21 \mathrm{U} / \mathrm{g} \mathrm{DM})$, amylases $(15.22 \pm 0.13 \mathrm{U} / \mathrm{g} \mathrm{DM})$, and
\end{abstract}

\section{Introduction}

In recent years, the use of antagonist microorganisms to phytopathogens, which results in a highly effective and environmental friendly biological control, is a promosing alternative to chemical pesticides that cause severe damages to human health, and to the environment by the creation of resistant to pesticides pests (Abo-Elyousr et al., 2014). Trichoderma is used as a biocontrol agent (BCA) against several pests (Sain and Pandey, 2016; Zachow et al., 2016). It plays an important role in the generation of natural compounds, particularly in the development of biopesticide formulation to gain ground on the chemical pesticides (Navaneetha et al., 2015). Thus, the production of high amounts of fungicidal metabolites of biological control agents (BCA) is necessary, and hence currently there are several production processes of different microorganisms; the solid-state fermentation (SSF) being the optimal choice. SSF is a biotechnological process, involving the use of solid substrates in the absence of free water (Couto and Sanromán, 2006; Carboué et al., 2017). Nowadays, the most important applications of SSF are enzyme production (lipases, cellulases, chitinases, amylases etc.), secondary metabolites production (mycotoxins, polycketides, lactones like 6-pentyl-alpha-pyrone (6-PP), peptaibols etc.), conidia production (biocatalysis, inoculum and biopesticides) and biomass (De la Cruz Quiroz et al., 2015; Sarhy-Bagnon et al., 2000; Gutiérrez-Sánchez et al., 2013). The selection of SSF as cultivation method is not only driven by quantitative and qualitative consideration, but it is also advantageous in terms of economical and ethical concerns related to environmental protection. SSF allows, in fact, a direct valorization of agricultural byproducts as the solid medium for fungal growth (Carboué et al., 2018).

Currently, an increasing trend is witnessed toward the use of effective agro-industrial wastes including wheat bran, sorghum pulp, tea or coffee wastes, sugarcane bagasse, etc. as wastes from the agricultural and food industries are produced in large quantities and are rich in carbohydrates and other nutrients amounts like proteins, amino acids, fats, fiber, and minerals can serve as substrates for the production of chemical compounds and enzymes by microorganisms using SSF, 
mainly due to their low cost. (De la Cruz-Quiroz et al., 2017b).

The valorization of part of agro-industrial wastes generated by Africa and Europe country under SSF was evaluated in a previous work (Hamrouni et al., 2019a). Results verified the possibility to use vine shoots, olive pomace, jatropha and potatoes flour as substrates to produce interesting metabolites by the fungi tested.

The most fermenter designs used in laboratory SSF processes are flasks or, Erlenmeyer bioreactors and Raimbault columns. In 1985, the feasibility of Raimbault column as bioreactor in SSF with sugarcane bagasse as support/substrate in SSF in order to produce Trichoderma harzianum conidias was demonstrated by Roussos (1985). However, one of the main challenges expected for the SSF process and fungi is the optimization of conidia and metabolites production. This is primarily ensured by an optimization of the growing medium but extrapolation of large-scale is a crucial step, especially if the essential objective is a wide-field application, therefore requiring higher conidias well as primary and secondary metabolites production. However, only limited information is actually available on the designs, evaluations of large scale bioreactors and suitable conditions to filamentous fungi growth and metabolites production (Singh et al., 2007; Millner, 2000). In this vein, the antifungal compounds production under SSF conditions using plastic single used bioreactors is a new and very interesting issue.

Hence, the aim present study was to evaluate a novel large scale solid state fermenter facilitating scale up studies at $9-11 \mathrm{~kg}$ substrate fresh capacity (material). A process for production of 6-pentyl-alphapyrone (antifungal metabolite), lytic enzymes (cellulases, lipase and amylase) by T. asperellumTF1 using a mix of vine shoots, jatropha, olive pomace and olive oil as substrates in plastic bag bioreactor, column bioreactors and flasks under identical conditions in parallel fermentation is described.

\section{Materials and methods}

\subsection{Origin of solid wastes used as substrate}

Vine shoots were supplied by the Laboratoire Européen d' Extraction (La Laupie-France) and were sieved in order to obtain particles with a size ranging $0.7-2 \mathrm{~mm}$. The Jatropha seed cake was obtained from a medium sized industry specialized in the production of Jatropha based biofuel in Burkina Faso. The olive pomace was obtained from a three phase olive mill (Coudoux-France) and was dried, grounded, fractioned $(300-1680 \mu \mathrm{m})$ and stored under low moisture conditions for further evaluation, while the potatoes flour was of French origin. The SSF was performed using a mixture of the above residues using different proportions expressed as \% dry matter.

Medium composition and proportion were selected after a screening and optimization of 6-PP, lytic enzymes and conidia production from SSF using Experimental design by Trichoderma strains (Hamrouni et al., 2019a).

\subsection{Microorganisms and culture conditions}

The strain of $T$. asperellum TF1was supplied by the IRD/IMBE (Institut de Recherche pour le Développement/Institut Méditerranéen de Biodiversité et d'Ecologie marine et continentale) fungi collection. The conidia of fungal strain were conserved in cryotubes with sterile beads TS/80-MX (Sigma-Aldrich, USA) and activated in sterilized PDA culture medium during 5 days at $30^{\circ} \mathrm{C}$.

To evaluate the apical growth, an aliquot of a colony was transferred to the center of a Petri dish containing PDA and incubated at $30^{\circ} \mathrm{C}$ during 4 days. Then, the mycelium apical growth (mm/day) was measured every $24 \mathrm{~h}$.

\subsection{Solid state fermentation (SSF)}

Solid State Fermentation was performed in flasks $(250 \mathrm{~mL})$, in Raimbault column (diameter of $2.5 \mathrm{~cm}$ and height of $20 \mathrm{~cm}$ ) and in plastic bag single used bioreactor $(20 \times 40 \times 60 \mathrm{~cm})$ made by Manudo (Montalieu-Vercieu, France), containing a mixture of vine shoots, jatropha cake, olive pomace, potatoes flour and olive oil as substrates in 30-20-20-20-10\% proportion, respectively (Fig. 1). The culture medium [5.5 Kg dry matter (DM)] was mixed with distilled water $(2.75 \mathrm{~L})$, autoclaved at $121{ }^{\circ} \mathrm{C}$ for $90 \mathrm{~min}$ and inoculated with a conidia suspension (2.8 L) at a concentration of $2 \times 10^{7}$ conidia. These steps were

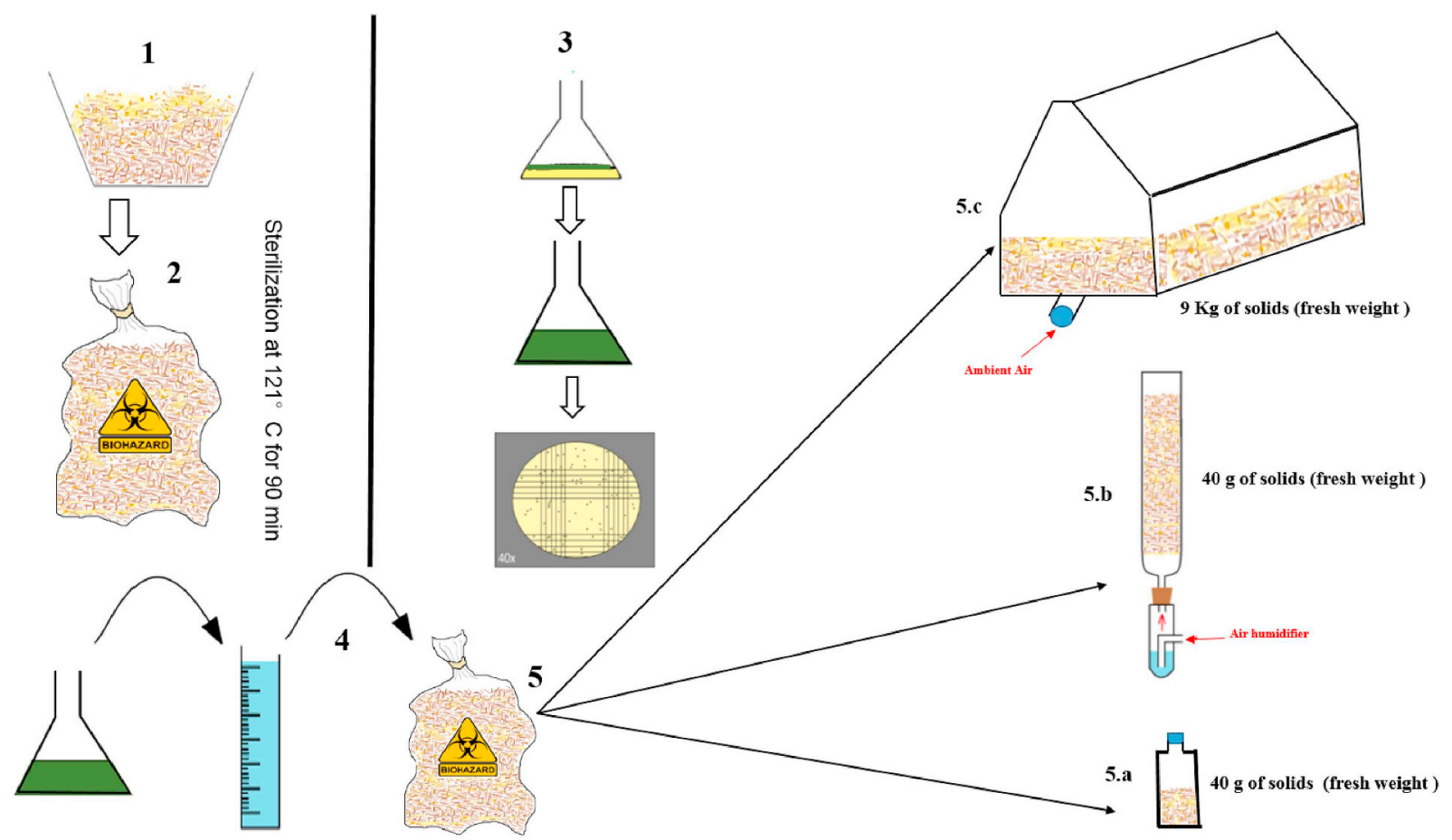

Fig. 1. Schematic representation of the SSF system, 1. Mixed substrates, 2. Sterilization at $121^{\circ} \mathrm{C}$ for $90 \mathrm{~min}$, 3. Inoculum preparation, 4. Inoculation, 5. Distribution: 5. a. Flasks bioreactor 5. bRaimbault column, 5. csingle used bioreactor. 
performed to prepare a substrate with initial moisture content of $50 \%$, in order to start the fermentation. Then, the inoculated substrate was distributed in flasks ( $40 \mathrm{~g}$ frech materia), glass columns and single used bioreactor ( $9 \mathrm{~kg}$ frech materia). Cultures were carried out at $29^{\circ} \mathrm{C}$ for 7 days.

Fermentations were controlled with the application of forced humid air during all processes. The aeration was generated by an air compressor with an initial rate of $4 \mathrm{~L}$ of saturated humid air/hour. For the single used bioreactor, the aeration flow rate ranged $4 \mathrm{~L} / \mathrm{min}$ to $200 \mathrm{~L}$ of ambient air/min.

Flasks were not hermetically closed in order to allow oxygen to flow by diffusion (passive aeration). To monitor the fermentation parameters, fermented substrates were collected in various intervals and stored at $-20{ }^{\circ} \mathrm{C}$ for further analyses.

\subsection{Conidia counting for determination of sporulation index}

Sporulation of T. asperellum was monitored over one week using the following procedure: $100 \mathrm{~mL}$ of sterile distilled water containing $0.01 \%$ $(\mathrm{v} / \mathrm{v})$ Tween 80 were added to each Erlenmeyer flask containing the strains grown on PDA medium and stirred with a sterile magnetic bar introduced at the same time for $30 \mathrm{~min}$. Then, $100 \mu \mathrm{L}$ of the suspension was transferred on a Mallassez cell and the number of conidia was counted on 10 squares and the mean value was determined. This number was corrected by the dilution factor and reported per $g$ of dry matter. For conidia enumeration in the mixture of substrates, the same procedure was adopted using a $1 \mathrm{~g}$ (fresh materia) of the fermented material after homogenization of the entire substrate (Roussos et al., 1997). Each counting was performed in triplicate. The results are expressed as $\%$ conidia $=$ mean \pm standard deviation.

\subsection{Moisture determination}

For water content determination, $1 \mathrm{~g}$ of fresh fermented material was introduced into a lab oven at $105^{\circ} \mathrm{C}$ for $24 \mathrm{~h}$. The following equation was used to calculate the moisture level:

Moisture $(\%)=\underline{\text { (Substrate fresh weight-dry weight }) * 100}$.

Substrate fresh weight.

All results are expressed as g of dry matter (DM).

\section{6. $p H$ determination}

The fermented substrate $(1 \mathrm{~g})$ was added into $20 \mathrm{~mL}$ of distilled water in a Falcon ${ }^{\circledR}$ tube.

This mixture was ground with Ultra Turrax to obtain a liquid solid suspension and then the $\mathrm{pH}$ of the suspension was determined using $\mathrm{pH}$ meter (HANNA HI 9126).

\subsection{Enzyme activity determination}

The fermented material $(1 \mathrm{~g})$ was placed in a Falcon ${ }^{\circledR}$ tube with $20 \mathrm{~mL}$ of distilled water. The enzymatic extract was homogenized in an Ultra-turax (1 min) to obtain a liquid solid suspension for further determination of enzyme activity.

Amylase activity was measured using soluble starch (1\%) in phosphate buffer (0.1 M, pH 7.0) at $50^{\circ} \mathrm{C}$ for $10 \mathrm{~min}$ (Singh et al., 2014). Cellulases activities were determined using sodium carboxymethyl cellulose $(1 \%)$ in sodium citrate buffer $(50 \mathrm{mM}, \mathrm{pH} 4.8)$ at $50{ }^{\circ} \mathrm{C}$ for 30 min, in according with De la Cruz-Quiroz et al., (2017a, 2017b).

For the two enzymes determinations mentioned above, the corresponding activities were stopped with ice for $5 \mathrm{~min}$. Sugar concentration was determined after each enzyme reaction according to the amount of resulting reducing sugar using 3,5-dinitro salicylic acid (DNS) following the assay method described by Miller (1959). Each treatment was done in triplicates and monitored kinetically.

An enzyme activity (U) was defined as the amount of enzyme that catalyzes the release of $1 \mu \mathrm{mol}$ of glucose per minute. Lipase activities were determined using $0.5 \mathrm{~mL}$ of p-nitrophenyl octanoate $(25 \mathrm{mM})$ in phosphate buffer $(25 \mathrm{mM}, \mathrm{pH} 7.0)$ at $30^{\circ} \mathrm{C}$ for $30 \mathrm{~min}$ (Lopes et al., 2011). Lipase activity (U) were defined as the amount of enzyme required to release $1 \mu$ mole of p-nitrophenol per minute.

*Each treatment was done in triplicate and monitored kinetically. The results are expressed as activity $=$ mean \pm standard deviation.

\subsection{Analytical analysis of 6-PP}

\subsubsection{Extraction of 6-PP}

6-PP compounds were recovered by soxhlet extraction system from solid fermented material using pure heptane (99.7\%, Sigma Aldrich). Samples ( $10 \mathrm{~g}$ of the fresh fermented material) were co-distilled at $60{ }^{\circ} \mathrm{C}$ with $100 \mathrm{~mL}$ heptane $(99.7 \%$, Sigma Aldrich) for $45 \mathrm{~min}$. $\gamma$-undecanolactone $(0.08 \mathrm{mg})$ (99\%, Sigma-Aldrich) was added as an internal standard before extraction.

\subsubsection{GC analysis}

6-PP analysis was performed on an Agilent Technology gas chromatograph 7890A (GC) equipped with a split injector (split ratio 2:1) operated at $200{ }^{\circ} \mathrm{C}$ and a flame ionization detector at $260{ }^{\circ} \mathrm{C}$. Volatile constituents were separated on a Supelcowax capillary column (internal diameter: $0.25 \mathrm{~mm}$, length: $60 \mathrm{~m}$, film thickness: $0.25 \mu \mathrm{m}$ ). The carrier gas was $\mathrm{H}_{2}$ (column flow $1 \mathrm{~mL} / \mathrm{min}$ ). The oven temperature was set at $180^{\circ} \mathrm{C}$ for $30 \mathrm{~min}$, then raised to $230^{\circ} \mathrm{C}$ at $10^{\circ} \mathrm{C} / \mathrm{min}$ and a final extension at $230^{\circ} \mathrm{C}$ for $30 \mathrm{~min}$ was followed.

For 6-PP analysis, a repeatability analysis was performed; the treatment (extraction and analysis by GC) was repeated 10 times. The generation and the data treatment were performed using the Microsoft Excel 2016.

\subsection{Experimental design and statistical analysis}

All treatments were carried out in triplicate ( 3 independent batches of sausages were prepared). The experiments were designed and analyzed statistically by ANOVA. Specifically, 3-way ANOVA was applied for physicochemical parameters and microbiological analysis, while 2way ANOVA in the preliminary sensory evaluation. Duncan's multiple range test was used to determine significant differences among results (coefficients, ANOVA tables and significance $(P<0.05)$ were computed using Statistica v. 10.0).

\section{Results}

\subsection{Growth of T.asperellum TF1 on PDA}

The culture on PDA reveals that the growth rate was rapid and colonies become wooly and compact. The surface colony color was white and became greenish in time, visible after $24 \mathrm{~h}$ of cultivation. The apical growth was evaluated by measuring the distance covered by the fungus (mm/day) from the center of the Petri dish (point of inoculation) to its periphery, as it reflects the ability of fungus to grow rapidly at a specific temperature. On PDA medium, the mean apical growth rate of T. asperellum TF1 was $17 \pm 1 \mathrm{~mm} /$ day at $30^{\circ} \mathrm{C}$ (Fig. 2).

Fig. $2 \mathrm{~b}$ shows the development of $T$. asperellum TF1 on solid substrates using a mixture of vine shoots, olive pomace, jatropha cake, potatoes flour and olive oil during SSF. Indeed, at the beginning of the cultures, the solid material had a white color due to the development of the mycelium and after 7 days of fermentation, the color became green.

\subsection{Growth of T. asperellum cultivated into three different SSF devices}

\subsubsection{Evolution parameters during T. asperellum TF1 growth on single used bioreactor \\ The effect of incubation time on the weight of substrate, aeration,}



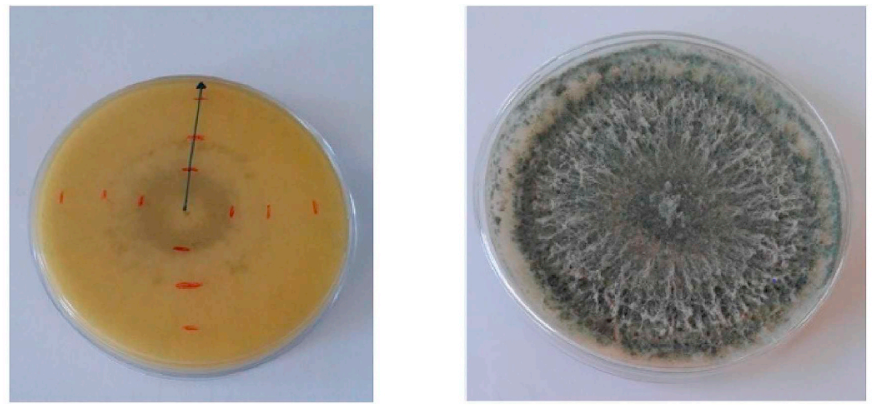

(a)
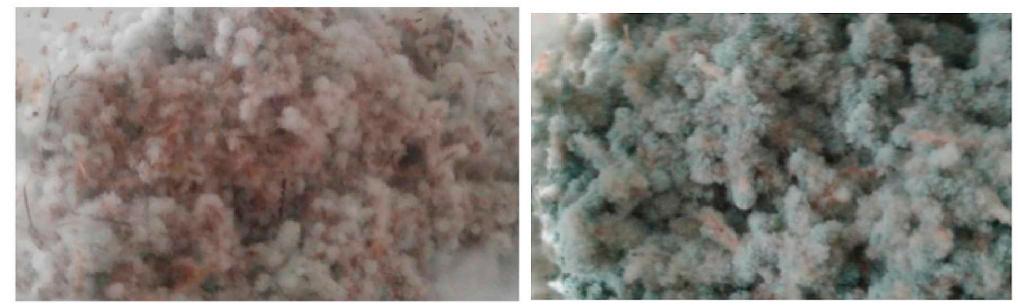

(b)

Fig. 2. Apical growth of T. asperellum TF1 colony on PDA (a) and aspect of fermented substrate (b).

Table 1

Evolution parameters during T. asperellumgrowth on SSF single used bioreactor cultivated at $22^{\circ} \mathrm{C}$ and aerated with compressed outdoor air.

\begin{tabular}{lllllll}
\hline Time $(\mathrm{h})$ & Weight $(\mathrm{kg})$ & Aeration $(\mathrm{L} / \mathrm{min})$ & Temperature $\left({ }^{\circ} \mathrm{C}\right)$ & Smell (Coco aroma) & Color (green) & Solid mix Humidity (\%) \\
\hline 0 & 9,2 & 4 & 23 & - & - & - \\
20 & 9 & 4 & 19 & - & - & 48,18 \\
44 & 8,74 & $20^{\mathrm{a}}$ & 45 & - & ++ & 46,68 \\
68 & 7,86 & 10 & 32 & +++ & ++ & 39,43 \\
92 & 7,36 & 7,5 & 33 & + & ++02 \\
120 & 7,02 & $30^{\mathrm{b}}$ & 18 & - & ++++ & 32,37 \\
168 & 6,2 & 32 & 18 & ++00 \\
\hline
\end{tabular}

- Absence.

+ Presence.

Legend.

${ }^{a}$ Aeration flow set at $20 \mathrm{~L} / \mathrm{min}$.

b Application of water stress, Aeration flow set at $30 \mathrm{~L} / \mathrm{min}$.

temperature, color of substrate, humidity (\%) and odor profile of $T$. asperellum TF1 culture in SSF on single used bioreactor was investigated (Table 1).

The weight of fermented substrate decreased after $44 \mathrm{~h}$ of culture. After $168 \mathrm{~h}$ (at the end of the experiment), the weight was $6.2 \mathrm{Kg}$ with $32 \mathrm{~L} \min ^{-1}$ of aeration.

The initial value of temperature was $23^{\circ} \mathrm{C}$ and then it increased to $45^{\circ} \mathrm{C}$ at $44 \mathrm{~h}$. The temperature remained constant at about $32{ }^{\circ} \mathrm{C}$ from $68 \mathrm{~h}$ to $120 \mathrm{~h}$ of incubation and then decreased to $18^{\circ} \mathrm{C}$ at the end of the process $(168 \mathrm{~h})$

Humidity (\%) was decreased from $48.18 \%$ to $38.00 \%$ at $168 \mathrm{~h}$ of incubation.

The intensity of the odor description was estimated on a 4 point scale $(+$ : weak odor, ++ : medium odor, +++ : strong odor, +++ + : very strong odor). Of note, strong coconut aroma was perceived after incubation for $92 \mathrm{~h}$.

\subsection{Production of enzymes}

For all systems tested, production of cellulases and amylase started at $20 \mathrm{~h}$ of incubation (Fig. 3). The highest enzymes production was obtained after $72 \mathrm{~h}$ of incubation using single used bioreactor. The maximum cellulases activity was observed after $44 \mathrm{~h}$ of incubation using Raimbault columns, reaching a production of up to $19.36 \pm 0.19$ $\mathrm{U} / \mathrm{g}$ DM on single used bioreactor at $72 \mathrm{~h}(19.25 \pm 0.08 \mathrm{U} / \mathrm{g} \mathrm{DM})$ and followed by incubation of the strain in flasks after $48 \mathrm{~h}(10.68 \pm 0.21$ $\mathrm{U} / \mathrm{g} \mathrm{DM})$.

The highest value of amylase was recorded at $72 \mathrm{~h}$ of cultivation on single used bioreactor $(15.22 \pm 0.13 \mathrm{U} / \mathrm{g} \mathrm{DM})$. However, it was not significantly $(P<0.05)$ different to $14.11 \pm 0.05 \mathrm{U} / \mathrm{g}$ DM obtained by cultivation on Raimbault columns. During cultivation on flasks, the maximum unit was $11.78 \pm 0.02 \mathrm{U} / \mathrm{g}$ DM at $48 \mathrm{~h}$.

Comparing both production systems, significant $(P<0.05)$ differences were observed on lipase production. Specifically, 26.74 $\pm 0.21 \mathrm{U} / \mathrm{g}$ DM was documented on flasks culture at $48 \mathrm{~h}, 30.44$ $\pm 0.05 \mathrm{U} / \mathrm{g}$ DM on Raimbault columns at $48 \mathrm{~h}$ and $38.73 \pm 0.01 \mathrm{U} / \mathrm{g}$ DM on single used bioreactor at $48 \mathrm{~h}$.

\subsection{Evolution of 6-PP}

The production of 6-PP from the fermentation on flasks by using $T$. asperellumTF1 started from the 44th hour of cultivation, increased to reach a maximum concentration of $1.69 \pm 0.08 \mathrm{mg}$. $\mathrm{gMD}^{-1}$ at $96 \mathrm{~h}$ and then decreased after around $100 \mathrm{~h}$ of fermentation (Fig. 4). Using forced aeration on Raimbault columns and single used bioreactor, the production of 6-PP started after 20 and $44 \mathrm{~h}$, respectively. The conditions applied on the single used bioreactor resulted in the optimum 6$\mathrm{PP}$ production, leading to $7.36 \pm 0.37 \mathrm{mg} / \mathrm{gMD}^{-1}$ at $92 \mathrm{~h}$, followed by cultivation with forced aeration on Raimbault columns system $\left(1.80 \pm 0.09 \mathrm{mg} / \mathrm{gMD}^{-1}\right.$ at $\left.76 \mathrm{~h}\right)$. 

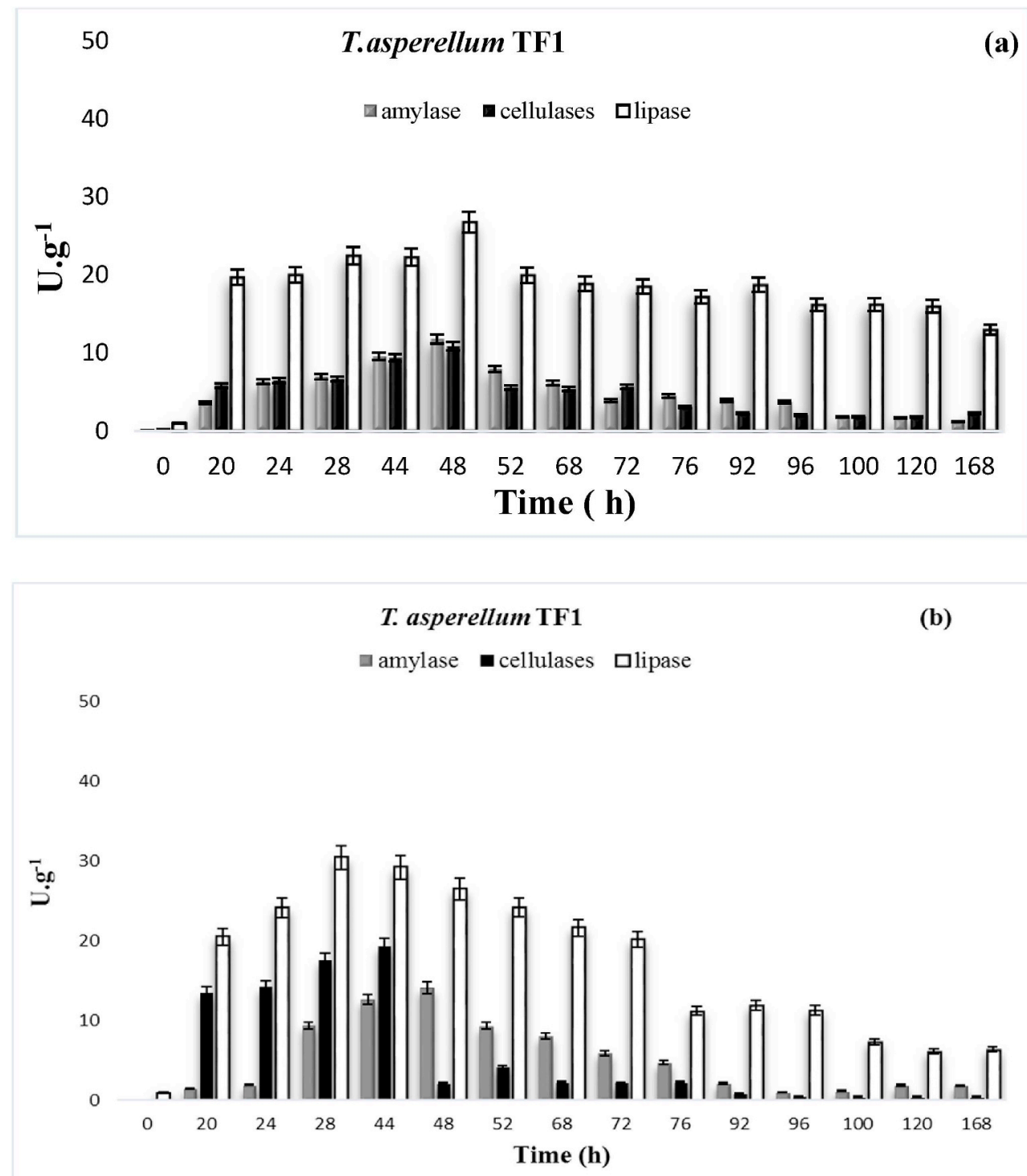

T. asperellum TF1

(c)

- 50 amylase $\mathbf{a}$ cellulases $\square$ lipase

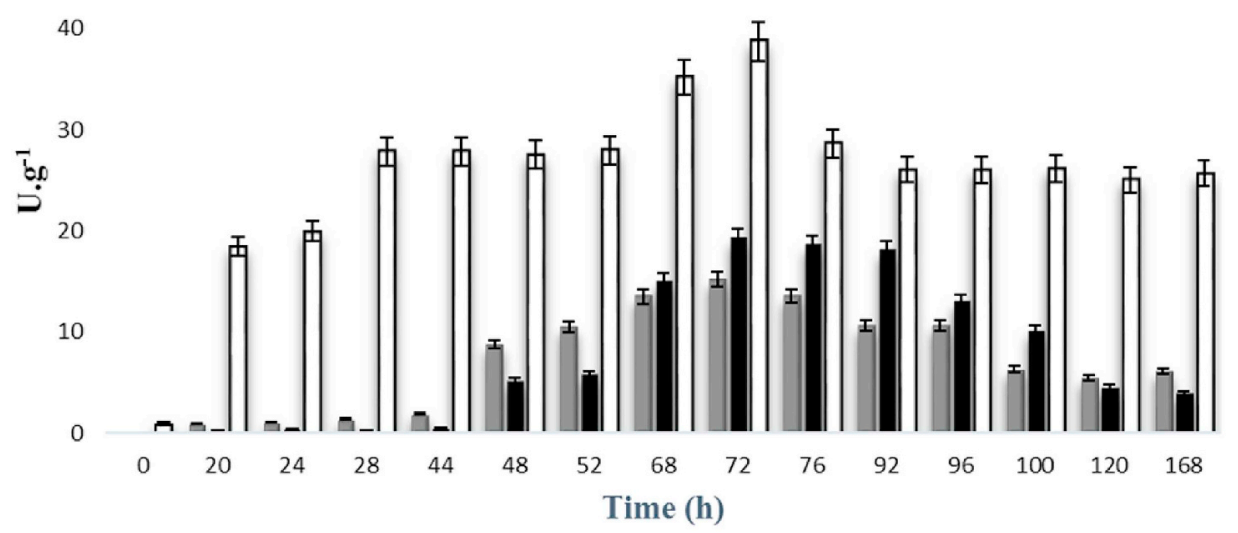

Fig. 3. Profile of lytic enzymes activities secreted by T. asperellum TF1 on SSF cultivated on flasks (a), Raimbault column (b), single used bioreactor (c). 


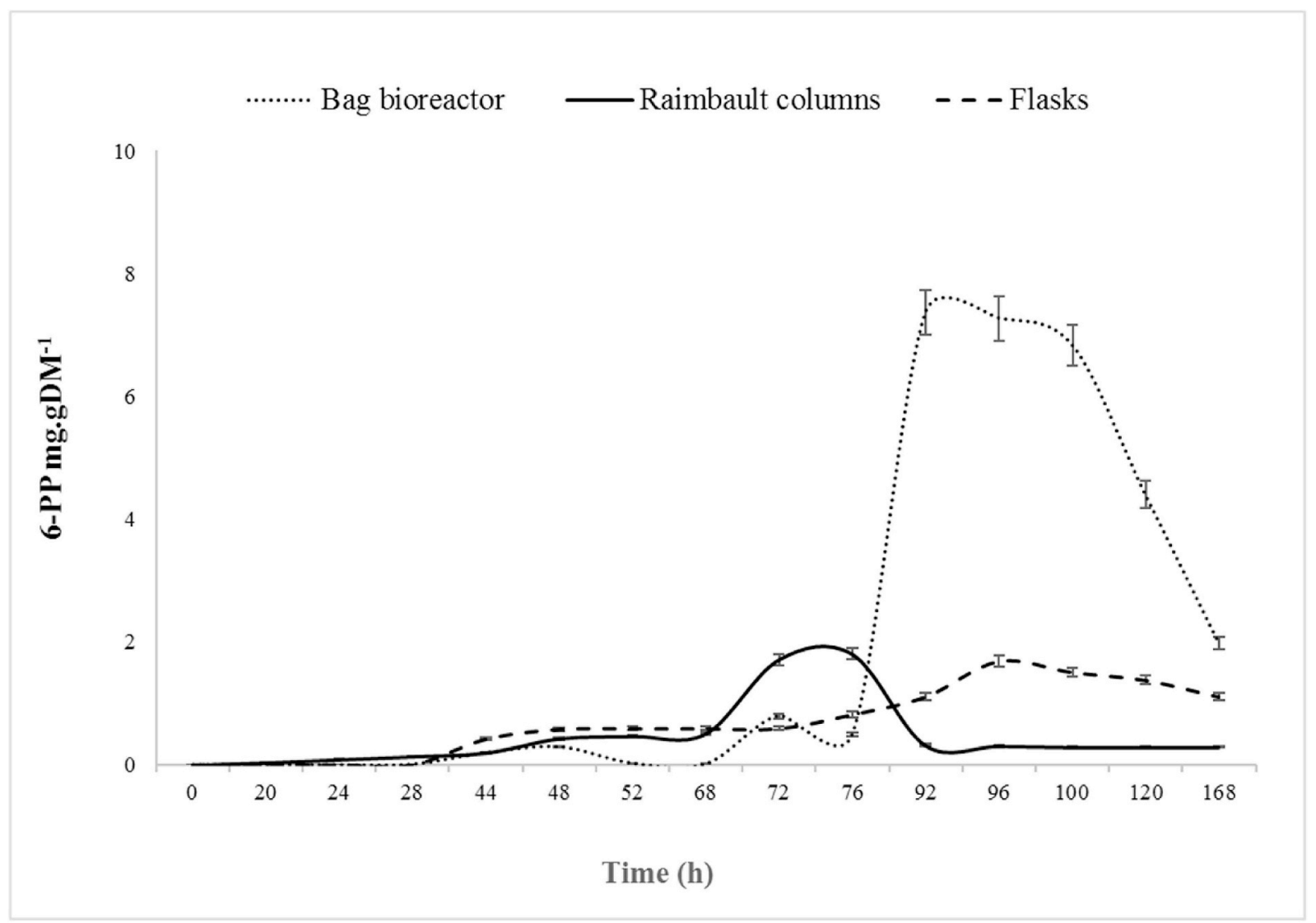

Fig. 4. Evolution of 6-PP production during the culture of T. asperellum TF1 on 3 Bioreactors.

\subsection{Sporulation index}

Fig. 5 summarizes the results obtained by T. asperellumTF1 in SSF using flasks, Raimbault columns, and single used bioreactor. An important issue is the high concentration observed in all systems, reaching over $1 \times 10^{8}$ spores/g on $168 \mathrm{~h}$ of culture time (Fig. 5). Such concentration is highly valuable for the production of fungal biocontrol agents, aiming at a feasible production process. In the present study, aeration generated increased conidia production in all cases. Importantly, the optimum index of conidia was achieved with the application of forced air through the single used bioreactor, whereas the lowest conidia production was observed on flasks without forced aeration. Among both systems evaluated, the highest quantity of conidia was noted by single used bioreactor $\left(85.48 \pm 0.04 \times 10^{8}\right.$ conidia/g DM) followed closely by the Raimbault columns $\left(16.17 \pm 0.08 \times 10^{8}\right.$ con$\mathrm{idia} / \mathrm{g} \mathrm{DM})$ and flasks $\left(4.90 \pm 0.24 \times 10^{8}\right.$ conidia/g DM).

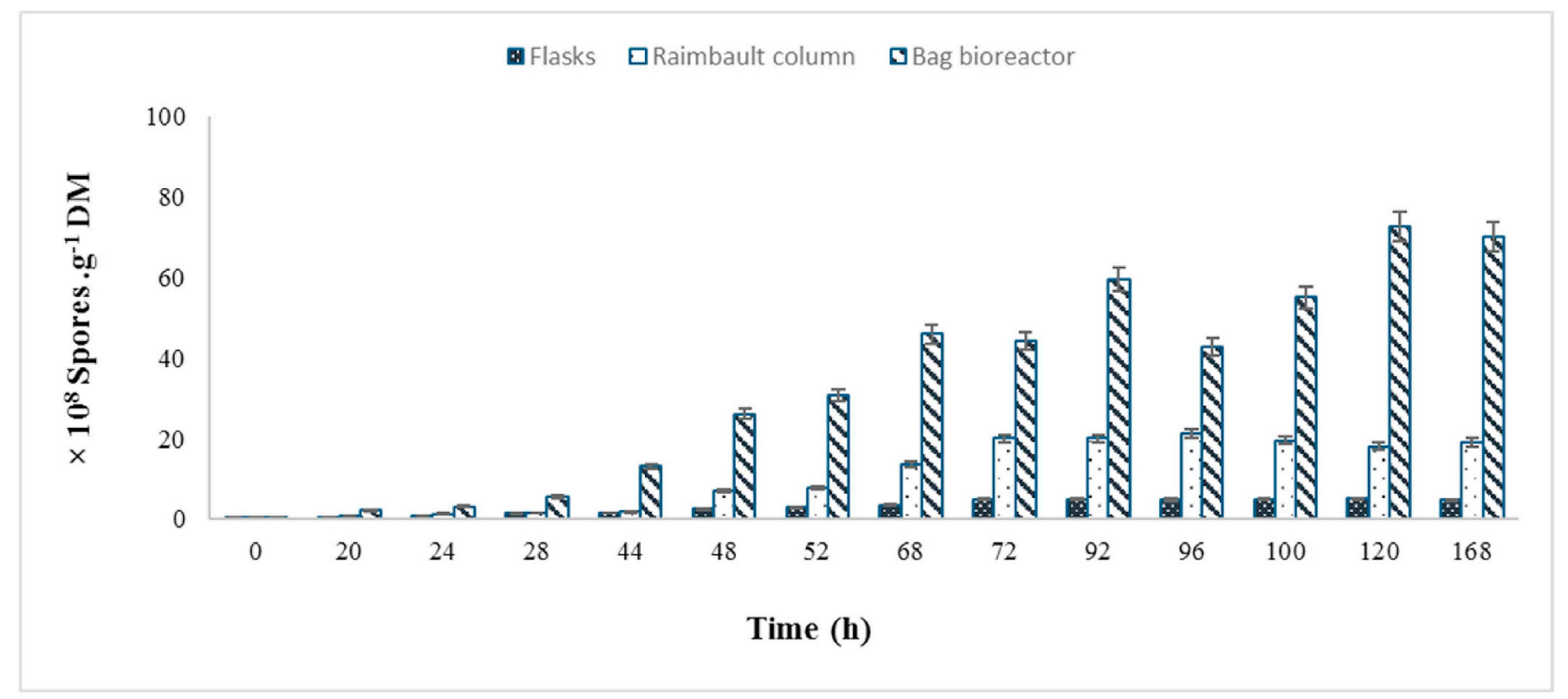

Fig. 5. Evaluation of conidia production by T. asperellum TF1 on SSF using flasks bioreactors, Raimbault column and plastic bag bioreactor. 
Table 2

The most significant values of the enzyme activities, conidia and 6-PP by $T$. asperellumTF1.

\begin{tabular}{|c|c|c|c|}
\hline & Flasksbioreactor & Raimbault column & Single used bag bioreactor \\
\hline \multicolumn{4}{|l|}{ Enzymes (U/g DM) } \\
\hline Cellulases & $10.68 \pm 0.21(48 \mathrm{~h})$ & $19.36 \pm 0.19(44 h)$ & $19.25 \pm 0.08(72 \mathrm{~h})$ \\
\hline Amylase & $11.78 \pm 0.02(48 \mathrm{~h})$ & $14.11 \pm 0.05(48 h)$ & $15.22 \pm 0.13(72 \mathrm{~h})$ \\
\hline Lipase & $26.74 \pm 0.21(48 h)$ & $30.44 \pm 0.05(48 \mathrm{~h})$ & $38.73 \pm 0.01(48 \mathrm{~h})$ \\
\hline Conidia $\left(\times 10^{8}\right.$ spores/g DM) & $4.90 \pm 0.24(92 \mathrm{~h})$ & $21,25 \pm 0.08(96 \mathrm{~h})$ & $85.48 \pm 0.04(120 \mathrm{~h})$ \\
\hline 6-PP (mg.gMD $\left.{ }^{-1}\right)$ & $1.69 \pm 0.08(96 \mathrm{~h})$ & $1.80 \pm 0.09(76 \mathrm{~h})$ & $7.36 \pm 0.37(92 \mathrm{~h})$ \\
\hline
\end{tabular}

The most important differences between the values of enzymatic activity, conidia and 6-PP are shown in Table 2. Overall, maximum 6$\mathrm{PP}$ production $\left(7.36 \pm 0.37 \mathrm{mg}\right.$. $\left.\mathrm{gDM}^{-1}\right)$, as well as content of lipases $(38.73 \pm 0.21 \mathrm{U} / \mathrm{g} \mathrm{DM})$, amylases $(15.22 \pm 0.13 \mathrm{U} / \mathrm{g} \mathrm{DM})$, and conidia $\left(8.55 \pm 0.04 \times 10^{9}\right.$ conidia/g DM) obtained on single used bioreactor were higher than those in the parallel fermentation in the laboratory scale column fermentor and flasks. In contrast, the maximum $(P<0.05)$ cellulases activities were recorded during cultivation on Raimbault column (19.36 $\pm 0.19 \mathrm{U} / \mathrm{g} \mathrm{DM})$ and single used bioreactor (19.25 \pm 0.08).

\section{Discussion}

Currently, a closer examination of SSF process in several research centers throughout the world has led to the realization of its economical and practical advantages. Indeed, a combination of medium and conditions of SSF leading to high yield in all essential parameters (conidia, enzymes, secondary metabolites, etc) is extremely difficult to achieve.

In addition, scale up practices are process specific, as only scarce information on bioreactors design and conditions on biomass production by fungus is available, while little is known on the particularities of a certain process at the onset of the fermentation development.

Conidia, lytic enzymes and 6-PP production under SSF conditions using single used bioreactors is a new and emerging issue. In the present work, a comparison of flasks bioreactors, Raimbault column and single used bioreactor under SSF conditions for the production of lytic enzymes, 6-PP and conidia by T. asperellum TF1 is proposed.

Use of single used bioreactor with the application of forced air on the SSF system had a positive effect on a group of enzymes (cellulases, amylases and lipases) produced at high titers by T. asperellum TF1. Production of these enzymes could be related to the necessity to maintain adequate and homogeneous levels of temperature and moisture into the system, allowing transfer of nutrients, metabolites and the oxygen solubilization (De los Santos-Villalobos et al., 2012). A reduced amount of all enzymes was noted in extracts obtained after incubation on laboratory flasks inoculated by T. asperellum TF, which suggested no enzyme tolerance to desiccation and temperature variation occurring in the fermented mass.

On the other hand, the production of enzymes by SSF is a topic currently under investigation, evaluating several approaches, including new bioreactor designs, substrates, fungal strains, etc (Raimbault and Alazard, 1980).

Although cellulases is the group of enzymes most studied on SSF. information on lipases, xylanases, proteases, and amylases, is also available in literature (Table 3 ).

The differences in the profile of cellulases production in flasks, Raimbault columns or single used bioreactor (Fig. 4) may be attributed to application of forced air into the fermentation system, which provided homogeneous environmental conditions, including the regulation of temperature and moisture, allowing improved transfer of nutrients, metabolites and oxygen diffusion through the solid substrate (Roussos et al., 1993; Durand, 2003; De los Santos-Villalobos et al., 2012; De la Cruz-Quiroz et al., 2017b).

In accordance to our findings, high cellulases activity was reported when an aeration rate of $2 \mathrm{mLmin}^{-1} \mathrm{~g}^{-1}$ was applied to a similar bioreactor (Raimbault columns system) using a mix of sugarcane bagasse, wheat bran, chitin, potato flour and olive oil as a substrate (De la Cruz-Quiroz et al., 2017a). Likewise, Roussos et al. (1993) reported a maximum cellulases yield of $135.26 \mathrm{U} / \mathrm{g} \mathrm{DM}$ and $131.64 \mathrm{U} / \mathrm{g}$ DM by Trichoderma harzianum CCM F-470 cultivated in parallel fermentation under identical conditions in a large scale solid state fermenter, designated as Zymotis and in laboratory column fermenter, respectively, using a mix of sugarcane bagasse and wheat bran impregnated to $75 \%$ humidity with mineral salt solution. The high cellulases activity obtained under zymotis bioreactor was attributed to the improved control of cultural parameters. The production of cellulases using SSF process was also reported for other filamentous fungi. For example, Bansal et al. (2012) recorded 31.0 U/g DM of cellulases by Aspergillus niger NS2 using wheat bran as a substrate on an Erlenmeyer bioreactor at $30^{\circ} \mathrm{C}$. In a similar study, Abdel-Fatah et al. (2012) reported $1.67 \mathrm{U} / \mathrm{mL}$ and $1 \mathrm{U} /$ $\mathrm{mL}$ of cellulases using Aspergillus terreus DSM 826 cultivated at $30^{\circ} \mathrm{C}$ on rice straw and sugarcane bagasse. Different carbon (glucose, maltose, carboxymethyl cellulose, etc) and nitrogen $\left(\mathrm{NH}_{4} \mathrm{Cl}, \mathrm{KNO}_{3}, \mathrm{NaNO}_{3}\right.$, etc) sources to enhance the production of cellulases were tested.

A Raimbault column bioreactor was evaluated by Kalogeris et al. (2003) to enhance the cellulases activity from Thermoascus aurantiacus. They used wheat bran as substrate reporting high activity when an aeration rate of $5,10,15 \mathrm{~mL} \mathrm{~min}^{-1} \mathrm{~g}^{-1}$ was applied. The same values of aeration $(5,10$ and $15 \mathrm{~mL} \mathrm{~min}-1 \mathrm{~g}-1)$ were evaluated by Abdeshahian et al. (2011) in an SSF process using wheat bran as substrate, reporting an improvement in the cellulases activities from Aspergillus niger FTCC 5003.

Amylase is another important group of enzymes used in modern biotechnology especially in the process of starch hydrolysis. No statically difference on amylases activities observed during SSF with T. asperellum TF1 on Raimbault columns and single used bioreactor were observed. However, the production of amylase from SSF using flasks was less significant.

Ogbonna et al. (2014) reported a maximum production of 5.83 and $7.51 \mathrm{U}$ amylase/mL obtained by Penicillium sp. and Chrysosporium, respectively, cultivated on rice as carbon source. It was concluded that amylase production by fungal strains is influenced by the carbon source, pH and temperature. Singh et al. (2014) screened 4 fungal isolates (S1, S2, S3, and S4) on SSF for amylase production, using wheat bran impregnated with nutrient salt $\left(\mathrm{KH}_{2} \mathrm{PO}_{4}, \mathrm{NH}_{4} \mathrm{NO}_{3}, \mathrm{NaCl}, \mathrm{MgSO}_{4}\right)$ and $105.10 \pm 2.1,143.70 \pm 1.4,164.1 \pm 1.7$ and $113.40 \pm 0.9 \mathrm{U} /$ $\mathrm{g}$ DM was obtained after 3 days of fermentation, respectively. Of note, isolate S3 was identified as Aspergillus fumigatus NTCC 1222. The high amounts of amylase activity compared to the results presented in our study could be partly due to supplementation with nutrient salts, enhancing the production of amylase in contrast to tap or distilled water applied in our case. Recently, De la Cruz-Quiroz et al. (2017a) reported a maximum of 28.33 and 33.68 amylases production by $T$. longibranchiatum and T. yunnanense, respectively, using Raimbault columns.

Alva et al. (2007) highlighted that the addition of starch, sucrose or glucose to the fermentation substrates provides higher amylase yields than the unsupplemented substrate.

Lipases activities was well produced in bag bioreactor systems by $T$. asperellum TF1 with forced aeration. In fact, a Raimbault columns system with and without forced aeration was previously evaluated by 
Table 3

Enzyme production by Trichoderma under culture conditions of SSF.

\begin{tabular}{|c|c|c|c|c|c|}
\hline Fungi & Substrate & Reactor & Enzyme & $\mathrm{U} / \mathrm{g}$ & References \\
\hline T. asperellum & Wheat bran & Erlenmeyer & Chitinase & 4.01 & Kumar et al. (2012) \\
\hline T. asperellum & Mango waste & Petri dishes & Exoglucanase & 1.8 & (De los Santos-Villalobos et al., 2012) \\
\hline T. harzianum & Castor seed paste, sugarcane bagasse, and olive oil & Erlenmeyer & Lipase & 4.00 & Coradi et al. (2013) \\
\hline \multirow[t]{2}{*}{ T. harzianum } & Wheat bran & Erlenmeyer & Endoglucanase & 4.10 & Pathak et al. (2014) \\
\hline & & & Exoglucanase & 0.74 & \\
\hline \multirow[t]{2}{*}{ T. asperellum } & Wheat bran & Erlenmeyer & Endoglucanase & 13.1 & Raghuwanshi et al. (2014) \\
\hline & & & Exoglucanase & 2.2 & \\
\hline T. longibrachiatum & sugarcane bagasse, wheat bran, chitin, potato flour and olive oil & Raimbault column & Amylase & 30.74 & (De la Cruz-Quiroz et al., 2017b) \\
\hline T.harzianum & Sugarcane bagasse & Zymotis & Cellulases & & Roussos et al. (1993) \\
\hline
\end{tabular}

De la Cruz-Quiroz et al. (2017a) to study lipases production using 6 Trichoderma strains (T. longibranchiatum, T. yunnanense, T. harzianum, T. asperellum $2-10$, T. asperellum $\mathrm{T} 2-31$ ) cultivated in parallel fermentation under identical conditions. It was reported that the highest value of lipases was produced by $T$. asperellum T2-10 (13.28 U/g) with forced aeration, although not significantly different to $11.88 \mathrm{U} / \mathrm{g}$ obtained by Trichoderma spp. with no forced aeration. The rest strains were affected negatively by forced aeration. The optimum enzyme activities were observed in strains T. harzianum and T. yunnanense under cultivation with no aeration, reaching up to 7.41 and $6.77 \mathrm{U} / \mathrm{g}$, respectively. Such a behavior suggests that the production of lipases from the genus Trichoderma is not related to the bioreactor system used due to possible minimal demand of oxygen. Therefore, the lipase activity may not be oxygen-limited.

Oliveira et al. (2017) have reported an improvement in lipase activity in a culture of Aspergillus ibericus using wheat bran with $10 \%$ of olive oil as substrate applying an aeration rate of $2 \mathrm{~mL} \mathrm{~min}^{-1} \mathrm{~g}^{-1}$. The authors reported that an aeration rate above $8 \mathrm{~mL} \mathrm{~min}^{-1} \mathrm{~g}^{-1}$ also has a negative effect on lipase activity and fungal growth was observed when they tested the SSF without aeration.

On a culture media during SSF, the development of mycelial biomass and subsequently high sporulation yields are related to a desiccation process, possibly owe to stress by the culture conditions, causing, thus, an increase in the concentration of conidia (RodríguezFernández et al., 2012; Carboué et al., 2017). This effect has a direct impact on the technical feasibility of conidia production because under such culture conditions, it is possible to use reactors like flasks, trays or bags resulting in energy saving, as far as air control and the laborious handling on the preparation of the fermentation process is concerned.

In this context, Flodman and Noureddini (2013) reported $7.50 \times 10^{8}$ conidia/g of $T$. reseei using corn cob wastes as a substrate on an Erlenmeyer bioreactor. Several stress conditions were tested to enhance the production of spores from fungi, such as twice mechanical mixes per day aiming at disrupting the hyphal network formed during the fermentation process. Theoretically, it was an interesting test, but the results were not as high as initially estimated. In contrast, our results indicated that $T$. asperellum TF1 growth on single used bioreactor produced $85.48 \times 10^{8}$ conidia/g DM, confirming data reported previously by Singh et al. (2007) during investigation of Trichoderma harzianum sporulation using tea leaves as substrate on a single used bioreactor. Their study suggested that the forced aeration applied during the fermentation process had a high influence on the stimulation of fungal sporulation $\left(8 \times 10^{8}\right.$ spores.g $\left.^{-1}\right)$.

Additionally, production of conidia from Trichoderma asperellum T210 was evaluated during SSF by De la Cruz-Quiroz et al. (2017b). A sporulation index of $1.4 \times 10^{9}$ spores/g using corn cob as substrate and polyethylene bioreactors was recorded. A production of $1.8 \times 10^{8}$ conidia/g was also reported during cultivation of Clonostachysrosea in polyethylene bioreactor using rice grains as substrate (Viccini et al., 2007).

Motta and Santana (2014) studied conidia production from T. reseei under SSF conditions in a column bioreactor and obtained a production of $4.41 \times 10^{9}$ conidia/g using empty fruit bunch. Similarly, Durand (2003) reported important conidia production by $T$. viride on scale sterile reactor $\left(5.5 \times 10^{9}\right.$ conidia/g) using sugar beet pulp medium on SSF.

On the other hand, Arzumanov et al. (2005) evaluated the interaction between moisture and aeration on conidia production by $\mathrm{Me}$ tarhizium anisopliae, an enthomopathogenic fungus. The cultivation was performed in column bioreactors using rice as the substrate during SSF. A range of air flow levels $\left(0-80 \mathrm{~mL}^{-1} \mathrm{~min}^{-1} \mathrm{~g}^{-1}\right)$ was applied to five different moisture treatments $(45,52,57,58$ and $65 \%)$, but no interaction between the two factors was reported. In addition, forced aeration was not considered necessary for sporulation, as it was not oxygenlimited, although it is known that $M$. anisopliae can sporulate successfully by forced aeration.

Regarding 6-PP production, comparison of the three bioreactor systems revealed marginally higher titers in single used bioreactors compared to other systems tested, probably due to improved control of cultural parameters. A reduction in the 6-PP formation was observed after $100 \mathrm{~h}$ when T. asperellum TF1 was cultivated in flasks. However, the decrease was higher when single used bioreactor with forced aeration was used. Similar reductions were also observed in column fermenter, indicating that they might be due to reasons other than deficiency in the performance or design of the single used bioreactor.

The effect of forced aeration on 6-PP production from T. asperellum TF1 was also evaluated in a previous work (Hamrouni et al., 2019b) and the results suggested that forced aeration on SSF systems leads to production of high amounts.

In literature, there are many studies available aiming at optimizing 6-PP production in solid and liquid culture (Ladeira et al., 2010) developing extraction fermentation processes Oda et al., (2009) and scaling-up an extraction fermentation process (Rocha-Valadez et al., 2006), however, investigations on scaling up 6-PP production on mix substrates under SSF using different bioreactors are still scarce.

The decrease of 6-PP production was reported in liquid medium fermentation but it was not observed in the solid-state fermentation, as reported by Sarhy-Bagnon et al., (2000). The authors explained that the inhibitory effect of 6-PP appeared to be responsible for low concentrations obtained in liquid medium.

\section{Conclusion}

Higher 6-PP concentration, enzyme titers, and conidia in single used bioreactor at mixed substrate (vine shoot, jatropha cake, olive pomace, potatoes flour and olive olive) loads, compared to laboratory scale column fermenter and flasks systems were recorded, indicating the suitability of the single used bioreactor configuration for use in SSF processes. The system was able to process $5-7 \mathrm{~kg}$ solid DM (solid medium), while the ease of operation and design simplicity were considered attractive features, which could lead to immediate technology transfer and adoption by the agricultural and industrial sector.

The culture conditions confirmed the validity of the single used bioreactor to produce 6-PP, conidia, and hydrolase enzymes, whereas 
fermentation processes were performed for $92 \mathrm{~h}$ to recover the maximum of all the metabolites. Scale-up may pave a way for efficient validation of the system effectiveness and economic evaluation the SSF processes.

\section{Acknowledgments}

Authors thank the planning direction office of Aix Marseille University for the support and technical facilities. Author Hamrouni thank Tunisian Republic "Tunis El Manar University" and "Higher Institute for Biotechnology - University of Manouba", the Institut de Recherche pour le Development (IRD), the Institut Méditerranéen de Biodiversité et d'Ecologie Marine et Continentale (IMBE).

\section{References}

Abdel-Fatah, O.M., Hassan, M.M., Elshafei, A.M., Haroun, B.M., Atta, H.M., Othman, A.M., 2012. Physiological studies on carboxymethyl cellulase formation by Aspergillus terreus DSM 826. Braz. J. Microbiol. 43, 1-11.

Abdeshahian, P., Samat, N., Hamid, A.A., Yusoff, W.M.W., 2011. Solid substrate fermentation for cellulase production using palm kernel cake as a renewable lignocellulosic source in packed-bed bioreactor. Biotechnol. Bioprocess Eng. 16 (2), $238-244$.

Abo-Elyousr, K.A.M., Abdel-Hafez, S.I.I., Abdel-Rahim, I.R., 2014. Isolation of Trichoderma and evaluation of their antagonistic potential against Alternaria porri. J. Phytopathol. 162, 567-574.

Alva, S., Anupama, J., Savla, J., Chiu, Y.Y., Vyshali, P., Shruti, M., Yogeetha, B.S., Bhavya, D., Purvi, J., Ruchi, K., Kumudini, B.S., Varalakshmi, 2007. Production and characterization of fungal amylase enzyme isolated from Aspergillus sp. JGI 12 in solid state culture. Afr. J. Biotechnol. 6, 576-581.

Arzumanov, T., Jenkins, N., Roussos, S., 2005. Effect of aeration and substrate moisture content on sporulation of Metarhiziumanisopliae var. acridum. Process Biochem. 40, 1037-1042.

Bansal, N., Tewari, R., Soni, R., Soni, K., 2012. Production of cellulases from Aspergillusniger NS-2 in solid state fermentation on agricultural and kitchen waste residues. Waste Manag. 32, 1341-1346.

Carboué, Q., Perraud-Gaime, I., Tranier, M.S., Roussos, S., 2017. Production of microbial enzymes by solid state fermentation for food applications. In: Ray, R.C., Rosell, C.M. (Eds.), Microbial Enzyme Technology for Food Applications. CRC Press, Boca Raton, pp. 437-451.

Carboué, Q., Claeys-Bruno, M., Bombarda, I., Sergent, M., Jolain, J., Roussos, S., 2018. Experimental design and solid state fermentation: a holistic approach to improve cultural medium for the production of fungal secondary metabolites. Chemometr. Intell. Lab. Syst. 176, 101-107.

Coradi, G.V., da Visitação, V.L., De Lima, E.A., Saito, L.Y.T., Palmieri, D.A., Takita, M.A., de Oliva Neto, P., de Lima, V.M.G., 2013. Comparing submerged and solid-statefermentationof agro-industrial residues for the production and characterization of lipase by Trichodermaharzianum. AnnalsofMicrobiology 63, 533-540.

Couto, S.R., Sanromán, M.Á., 2006. Application of solid-state fermentation to food industry - a review. J. Food Eng. 76, 291-302.

De la Cruz Quiroz, R., Roussos, S., Hernández, D., Rodríguez, R., Castillo, F., Aguilar, C.N., 2015. Challenges and opportunities of the bio-pesticides production by solidstate fermentation: filamentous fungi as a model. Crit. Rev. Biotechnol. 35, 326-333.

De la Cruz-Quiroz, R., Robledo-Padilla, F., Aguilar, C.N., Roussos, S., 2017a. Forced Aeration Influence on the Production of Spores by Trichoderma strains. Waste Biomass Valori. 8, 2263-2270.

De la Cruz-Quiroz, R., Roussos, S., Hernandez-Castillo, D., Rodríguez-Herrera, R., LópezLópez, L.I., Castillo, F., Aguilar, C.N., 2017b. Solid-state fermentation in a bag bioreactor: effect of corn cob mixed with phytopathogen biomass on spore and cellulase production by Trichoderma asperellum. Intech: Fermentation Processes 3, $43-56$.

De los Santos-Villalobos, S., Hernández-Rodríguez, L.E., Villaseñor-Ortega, F., PeñaCabriales, J.J., 2012. Production of Trichodermaasperellum T8a spores by a "homemade" solid-statefermentationof mango industrial wastes. BioResources 7 , 4938-4951.

Durand, A., 2003. Bioreactor designs for solid state fermentation. Biochem. Eng. J. 13, $113-125$.

Flodman, H.R., Noureddini, H., 2013. Effects of intermittent mechanical mixing on solidstate fermentation of wet corn distillers grain with Trichoderma reesei. Biochem. Eng. J. 81, 24-28.

Gutiérrez-Sánchez, G., Roussos, S., Augur, C., 2013. Effect of caffeine concentration on biomass production, caffeine degradation, and morphology of Aspergillus tamarii. Folia Microbiol. 58, 195-200.

Hamrouni, R., Claeys-bruno, M., Molinet, J., Masmoudi, A., Roussos, S., Dupuy, N., 2019a. Challenges of enzymes, Conidia and 6-Pentyl-Alpha-Pyrone Productionfrom
Solid State Fermentation of Agroindustrial Wastes using Experimental Design and T. Asperellum Strains. Submitted for publication in Waste Biomass Valori.

Hamrouni, R., Molinet, J., Dupuy, N., Taieb, N., Carboué, Q., Masmoudi, A., Roussos, S., 2019b. The Effect of Aeration for 6-Pentyl-Alpha-Pyrone, Conidia and Lytic Enzymes Production by Trichoderma Asperellum Strains Grown in Solid-State Fermentation. Submitted for publication in Waste Biomass Valori.

Kalogeris, E., Iniotaki, F., Topakas, E., Christakopoulos, P., Kekos, D., Macris, B.J., 2003. Performance of an intermittent agitation rotating drum type bioreactor for solid-state fermentation of wheat straw. Bioresour. Technol. 86 (3), 207-213.

Kumar, D.P., Singh, R.K., Anupama, P.D., Solanki, M.K., Kumar, S., Srivastava, A.K., Singhal, P.K., Arora, D.K., 2012. Studies on Exo-Chitinase Production from Trichoderma asperellum UTP-16 and Its Characterization. Indian J. Microbiol. 52, 388-395.

Ladeira, N.C., Peixoto, V.J., Penha, M.P., De Paula Barros, E.B., Leite, S.G.F., 2010. Optimization of 6-pentyl-alpha-pyrone production by solid state fermentation using sugarcane bagasse as residue. Bioresources 5, 2297-2306.

Lopes, D.B., Fraga, L.P., Fleuri, L.F., Macedo, G.A., 2011. Lipase and esterase: to what extent can this classification be applied accurately? FoodScience and Technology 31 , 603-613.

Miller, G.L., 1959. Use of dinitrosalicylic acid reagent for determination of reducing sugar. Anal. Chem. 31, 426-428.

Millner, R.J., 2000. Current status of Metarhizium as mycoinsecticide in Australia Biocontrol News Inf. 21, 47-50.

Motta, F.L., Santana, M.H.A., 2014. Solid-state fermentation for humic acids production by a Trichoderma reesei strain using an oil palm empty fruit bunch as the substrate. Appl. Biochem. Biotechnol. 172, 2205-2217.

Navaneetha, T., Prasad, R., Venkateswar Rao, L., 2015. Biopesticides liquid formulation of Trichoderma species for management of gray mold in Castor (ricinuscommunis L.) and alternariaster leaf blight in sunflower. J. Biofertil.Biopestic. 6, 1-11.

Oda, S., Isshiki, K., Ohashi, S., 2009. Productionof 6- pentyl-a-pyronewithT.atroviride and its mutant a novel extractive liquid-surface immobilization (EXT-LSI) system. Process Biochem. 44, 625-630.

Ogbonna, C.N., Okpokwu, N.M., Okafor, C.U., Onyia, C.E., 2014. Isolation and screening of amylase producing fungi obtained from garri processing site. Int. J. Biotechnol. F. Sci. 2, 88-93.

Oliveira, F., Salgado, J.M., Abrunhosa, L., Pérez-Rodríguez, N., Domínguez, J.M., Venâncio, A., Belo, I., 2017. Optimization of lipase production by solid-state fermentation of olive pomace: from flask to laboratory-scale packed-bed bioreactor. Bioprocess Biosyst. Eng. 40 (7), 1123-1132.

Pathak, P., Bhardwaj, N.K., Singh, A.K., 2014. Production of Crude Cellulase and xylanase from Trichoderma harzianum PPDDN10 NFCCI-2925 and its application in photocopier waste paper recycling. Appl. Biochem. Biotechnol. 172, 3776-3797.

Raghuwanshi, S., Deswal, D., Karp, M., Kuhad, R.C., 2014. Bioprocessing of enhanced cellulase production from a mutant of Trichoderma asperellum RCK2011 and its application in hydrolysis of cellulose. Fuel 124, 183-189.

Raimbault, M., Alazard, D., 1980. Culture method to study fungal growth in solid fermentation. Eur. J. Appl. Microbiol. Biotechnol. 9, 199-209.

Rocha-Valadez, J.A., Estrada, M., Galindo, E., Serrano-Carreón, L., 2006. From shake flasks to stirred fermentors: scale-up of an extractive fermentation process for 6 pentyl- $\alpha$-pyrone production by Trichoderma harzianum using volumetric power input. Process Biochem. 41, 1347-1352.

Rodríguez-Fernández, D.E., Rodríguez-León, J.A., de Carvalho, J.C., Karp, S.G., Sturm, W., Parada, J.L., Soccol, C.R., 2012. Influence of airflow intensity on phytase production by solid-state fermentation. Bioresour. Technol. 118, 603-606.

Roussos, S., 1985. Croissance de Trichoderma harzianum par Fermentation en Milieu Solide : Physiologie, Sporulation et Production de Cellulases. Thèse de doctorat. Université de Marseille, pp. 188.

Roussos, S., Raimbault, M., Prebois, J.P., Lonsane, B.K., 1993. Zymotis, a large scale solid state fermenter - design and evaluation. Appl. Microbiol. Biotechnol. 42, 37-52.

Roussos, S., Lonsane, B.K., Raimbault, M., Viniegra Gonzalez, G., 1997. Advances in Solid State Fermentation. Kluwer Academic Publishers, Dordrecht, pp. 631.

Sain, S.K., Pandey, A.K., 2016. Biological spectrum of Trichoderma harzianum Rifaiisolatesto control fungal diseases of tomato (Solanumlycopersicon L.). Arch. Phytopatho. Plant Prot. 1-15.

Sarhy-Bagnon, V., Lozano, P., Saucedo-Castañeda, G., Roussos, S., 2000. Productionof 6 pentyl-alpha-pyrone by Trichoderma harzianum liquid and solid state cultures. Process Biochem. 36, 103-109.

Singh, A., Srivastava, S., Singh, H.B., 2007. Effect of substrates on growth and shelf life of Trichoderma harzianum and its use in biocontrol of diseases. Bioresour. Technol. 98, 470-473.

Singh, S., Singh, S., Bali, V., Sharma, L., Mangla, J., 2014. Production of fungal amylases using cheap, readily available agriresidues, for potential application in textile industry. BioMed Res. Int. https://doi.org/10.1155/2014/215748.

Viccini, G., Mannich, M., Fontana-Capalbo, D.M., Valdebenito-Sanhueza, R., Mitchell, D.A., 2007. Spore production in solid-state fermentation of rice by Clonostachys rosea, a biopesticide for gray mold of strawberries. Process Biochem. 42, 275-278.

Zachow, C., Berg, C., Müller, H., Monk, J., Berg, G., 2016. Endemic plants harbour specific Trichoderma communities with an exceptional potential for biocontrol of phytopathogens. J. Biotechnol. 235, 162-170. 